\title{
Toni Morrison’s (Re)visions: Dis-integrating Language in the Metafictional Novel Jazz
}

\author{
Silvia Ammary \\ John Cabot University, Rome, Italy
}

\begin{abstract}
Throughout Jazz (2004), Morrison revises language and stakes a generic revolution within her linguistic one. Problematising language, she interrogates its role by disrupting all metaphoric operation and normative operations of traditional Western narratology, challenging ontological distinction, and undermining a novelistic claim of/for reality. Morrison creates the novel as a parody of itself. As a metafictional object, she (re)visions the fiction with multiple agendas - a means to interrogate the reality of its constitution and to implicate the political consequences inherent in that constitutional process of construction. By creating a series of antagonisms, oppositions, contradictions, equivalences, and intertextualities, Morrison transforms (and transmutes) novelistic "hostility" into a generic "trauma” simultaneously rendering it as realistic experience, historic event, personal story, collective memory, narrative device, and psychological phenomena. Exposing trauma by virtue of its linguistic symptoms, Morrison draws attention to the underlying mechanisms, structures, and apparatuses of Western linguistic codes that determine, produce, and maintain the ultimate (un)knowability of the past. This paper will examine all these and how the elliptical tendency of language surfaces the psychological disfigurement of the characters within the form of linguistic codes revealing the metaphorical tendency in Jazz to manifest its own reflective construction (and self-conscious deconstruction).
\end{abstract}

Keywords: metafiction, postmodernism, (mis)-representation, simulation, cracks, memory

\section{Introduction}

Analyzing the novel Jazz (2004) through the lens of metafiction reveals many interesting aspects of the novel that have not been tackled yet. In fact, the whole novel is narrated by a metafictional narrator as it tells stories not only about its characters, but about itself as a cultural form as well. In fact, Toni Morrison’s novel Jazz (2004) exemplified the practice of metafiction as both a literary device and social theory, allowing us to negotiate novelistic conventions and the boundaries of the genre. Morrison constructs and transgresses the boundaries of her own novelistic creation, performing the word's disruption of convention and articulating her generic revolution. Perpetually and pathologically crossing the boundaries of the novel, Morrison interrogates what lies at stake in its ontological (in)differentiation.

The tendency of language to complicate, disrupt, disquiet, and negotiate the conventions of its own semantic medium—-the word—as a means of achieving its theoretical end—self-consciously challenges and

Silvia Ammary, Ph.D., The Department of English Langauge and Literature, John Cabot University. 
self-reflexively exposes the problem inherent in all forms and forums of representation. Literary and critical theorists attempt to make sense of this linguistic crisis by virtue of constructing systems of oppositions, binaries, antagonisms, and equivalences in order to analyze patterns, categorize tendencies, constitute realities, and consider their epistemologies, staking the word as both the cause of and the solution for the problem of representation. Morrison's novel Jazz posits the function (and dysfunction) of the language at the center of its novelistic investigation, interrogating the viability of language to articulate story and narrate history, and its inaccessibility. Playing upon the process of construction in her fiction, Morrison negotiates what lies at stake in the functionality of all constructions; that is, Morrison frames her novelistic agenda within a political one, juxtaposing and framing the fictional struggle to appropriate meaning with and within the semantic attempt to constitute reality. In this way, Morrison's texts transgress the boundaries of generic division and traverse the limitations of novelistic conventions, figuring an anti-theoretical theory of the novel; i.e., its theoretical position excludes its own ability to be theorized.

\section{Metafiction and Jazz}

As Waugh described in her insightful study Metafiction: The Theory and Practice of Self-conscious Fiction (1984), instead of grounding itself between binaries of literary theory, metafiction operates within a nexus of linguistic construction:

Metafiction is a term given to fictional writing which is self-consciously and systematically draws attention to its status as an artifact in order to pose questions about the relationship between fiction and reality. In providing a critique of their own methods of construction, such writings not only examine the fundamental structures of narrative fiction, they also explore the possible fictionality of the world outside the literary fictional text. (p. 2)

Exposing the arbitrary relation between the linguistic system and the external world to which it ostensibly refers, metafiction requires the reader to decipher the text's multiplicities, demonstrating how all texts are reduced to the "meta" terms of their own construction. Waugh (1984) described how "metafiction explores a theory of fiction through the practice of writing fiction” (p. 2), displaying its own artifice by self-reflexively and self-consciously exaggerating the impermanence and instability of its own linguistic construction. Instead of presenting metaficional theory as an external device to be applied to the novel, metafiction already exists within the form itself, situating its offensive in the internal structures of its own making. Waugh (1984) introduced a list of typical metafictional devices:

Incantatory and absurd lists; total breakdown of temporal and spatial organization of narrative, infinite regress, dehumanization of character, parodic doubles; obtrusive proper names, self-reflexive images, the story within the story, continuous undermining of specific fictional conventions, use of popular genres and explicit parody of previous texts. (p. 22)

All these serve to flaunt systematically the artifice of the text and expose the novel as construct. Morrison's Jazz speaks to the metafictional nature of all story-telling and identity making, suggesting the ways in which imitation and fabrication construct realities which could exist, but in reality do not. However, Morrison complicates her metafiction even further; embedding the fictionality of her narrative within the history to which it refers. At once staking the reality of an African past in the fictionality of the story's contemporary construction, she bridges and breaks the gap between divisions of fiction and reality; she speaks to what is lost in its absence, 
i.e., our (dis)ability to remember the past. The past remains forever removed from us, even linguistically. The trauma of not remembering a fragmented and dislocated history marks and renders the racialized, classed, and gendered circumstance of the individual and collective trauma she attempts to re-member. Morrison ultimately plays with the capacity of the novel to form itself "on its capacity to absorb, transform, and question the discourses of which it is constructed. It shows how the novel always retraces its boundaries, how it ingests the "real world" as discourse and is, in turn, reabsorbed by it" (Waugh, 1984, p. 148). Morrison literally and figuratively reabsorbs its lost remnants, limbs, and traces, perpetually burying and resurrecting the novel, and its parts within continual articulation of its realistic eulogy of the past and metaphoric rebirth in the present.

\section{The Epilogue and the Forward}

Morrison's Jazz foregrounds a national agenda inscribed within an individual one. That is, it tells a personal story, a collection of fragments, in order to speak about the collective history that circumscribes it. The process of fragmentation, division, dislocation, opposition, and contradiction all function as the operational mechanics of the novel's drive: The Jazz improvises its central melody and its multiple trajectories, ultimately stringing together the "loose threads" into the fabric of the novel's making. The novel is made up of 10 sections with no numbered divisions or chapter heading, following each other with unequal length and they pick up the story at unexpected places in the narrative track. The epilogue provides and foreshadows this process of narrative and generic subversion:

I am the name of the sound

And the sound of the name.

I am the sign of the letter

And the designation of the division. (Morrison, 2004, p. xvi)

The juxtaposition between the oral tradition (the first two lines) and the written tradition (the second two lines) linguistically and visually sets up the groundwork of the novel, by which Morrison translates the "orality" of African American story-telling into "writerly" formality. The oral and the written are made dialogical: Morrison intersects and debates their confrontation, presenting the problem of representation as the novel's investigation. The speaker's claim in the epilogue for "the designation of the division" between the sign and the letter highlights the linguistic difference in the semiotic division between the sign and the signified, both reflecting the inherent fallacy to represent. The beginning of the novel, therefore, ultimately services its final agenda; the problematic of representation in terms of an individual identity, collective community, historical authenticity or fictional story.

The forward that introduces the novel frames the story, informing our reading of it as Morrison announces her failed attempt to write its opening line. The literal writing of the line and the figurative un-writing of it immediately performs the metafictional impulse that drives the rest of the novel. Although she "erases" the first lines of the actual text, we are nevertheless still reading them, allowing Morrison to achieve multiple "beginnings" to her story. Her rejection of the opening line, "it didn’t work" (Morrison, 2004, p. xv) foreshadows the "failure" of the narrative to make an authorial and autonomous sense of meaning. The opening line of the novel, "Sth, I know that woman" immediately defamiliarizes language: We hear the first word rather than read it. The manipulation of the word as both a written and oral device evidences Morrison's use of language as a private 
and unfamiliar form. The reference to "Sth" —an unknowable and unspeakable subject—is contrasted by the narrator's comment, "I know that woman" intersecting the process of familiarization and de-familiarization that complicates our ability to "read" the narration's private language. The narrator seems to know everything and nothing; the narrator evades any definition and any rules of narration. Like the music of jazz, it improvises. As Nowlin (1999) suggested, Morrison creates an "alien discourse" that "might reconnect her to the community she has left behind, "suggesting the private dialect as an attempt to speak to and about the tribal community she attempts to represent (p. 154). However, the articulation of this tribal form within a public forum-the popular realm of the novel—challenges and complicates any sense of pure connection to that tribal past, postulating its language as an intermediate between the public spaces of the novel and the private places of a culturally specific community. As Nowlin (1999) suggested: "What Morrison has in mind is a forgotten oral culture somehow embedded in the printed word, a latent harmony of sign, sound, and sense that unites speaker and auditor and continuously (re)creates the community it addresses” (p. 154).

\section{The Function of Dorcas}

Jazz becomes the underlying voice that tells the untold and unheard stories of its characters, relating the text's personal fiction to the communal history it represents. However, the narrator's perpetual interruption, improvisation, and deviation from her narrative draw attention to the story's artifice and expose the unreliability of its history. Jazz is, therefore, plagued with linguistic and thematic fractures in plot progression, personifying these cracks in the narrative as representative of the personal trauma and collective scars that threaten memory, story, and history. However, although the jazz-like tendencies of the novel's improvisation overwhelmingly fragments the characters into many "pieces”, this improvisation is ultimately united by the music/novel's central melody, offering a sense of refuge and a moment of consolation.

As Rubenstein argued in her article "Singing the Blues/Reclaiming Jazz: Toni Morrison and Cultural Mourning” (1998), the figure of Dorcas serves as the device that both divides and unites the story as both a personal narrative of loss and a collective narrative of gain:

The underlying melody is the death of Dorcas; her death is what ties the central characters_-Violet, Alice and Joe- together. Once the melody is set, each of the players in a jazz ensemble gives each of the characters the opportunity to sing the blues, even that of the dead girl Dorcas. (p. 37)

The literal death of Dorcas marks the figurative birth of the novel, allowing the narrator by extension of Violet, to retrace the history and re-member the "body" of the fractures past of the African American community. Although the narrator posits a notion of authority to "know" the body of Dorcas in the opening line, the rest of the story challenges that knowledge, marking Dorcas as the sign that is continuously signified, un-signified, and de-signified throughout the novel, exposing the self-reflexive quality of the story as a construction. The phenomenology of Dorcas marks the symptom—rather than the solution— to the very crisis that a hermeneutic study seeks to overcome. Dorcas is alienated to the ultimate sign of the text for the narrator and the reader to “decipher"—as meaning resides within her literal absence (death), metaphoric ambiguity (her malleability), and physicality (her blackness). Dorcas achieves a kind of resurrection by means of the photograph that Violet displays: "The photograph of a bold, unsmiling girl staring from the mantelpiece” (Morrison, 2004, p. 12). In other words, Dorcas exists as a mythic resonance rather than a physical presence. The omnipresent "visibility" of 
Dorcas throughout the story contrasts with the actual "invisibility" of her body—she is dead and buried before the story begins. The narrator exploits the reflexivity of the image form to represent the multiplicity of signification.

In this way, the "picture on the mantelpiece" does not isolate meaning but refract it, reflecting the multifunctional agenda of the novel's generic and political concerns. Eluding the viewer, the photograph is "an inward face-whatever it sees is its own self. You are there, it says, because I am looking at you” (Morrison, 2004, p. 12). "The inward face" of this photograph contrasts with the conventional notion of the photographic image as an "outward” representation. Instead, the photography's obscurity and its threatening inwardness elude and exclude the form as a site of representation. It exists only by virtue of observation, demanding an observer to enact its visuality, which draws attention to the voyeuristic nature of the narrator and by extension the reader.

The novel locates Dorcas as the beloved - the object of desire-and the subject to be feared, for she enacts a perverted love, familiarizing and de-familiarizing our conventional notion of the loved/beloved relationship, in which she simultaneously attracts our sympathy and evokes our moral austerity. If jazz is the novel's melody, then love is its song. However, Morrison's form of love becomes a function of the novel's complication - a perverse love that spoils its participations; it is a love that is at once abstractly beautiful and dangerously real: "So she decided to love-well, find out about-the eighteen years old whose creamy little face she tried to cut open” (Morrison, 2004, p. 5). Violet's decision to love enacts a perverse violence, drawing attention to the narrative's unconventional treatment of love as a generic trope and foreshadowing the linguistic blurring between Violet and violent. The narrator describes Violet's literal investigation into the body of the dead girl as a process of detection, affection, and obsession, allowing her narrative to both thematically and linguistically perform this complex rendition of love: "It was watching an old street pigeon pecking the crust of a sardine sandwich the cat left behind" (Morrison, 2004, p. 6). This layering of watching-seeing Violet and reading the narration of her seeing-imitates the "pecking of the crust" - the effaced body of Dorcas and the disjointed body of narrative, figuratively reducing Dorcas into her metaphorical remainder (a memory) into a metafictional one (a story). Morrison aligns Violet's perverse form of love with the narrator's abusive transgression of boundaries; the narrative performs a dissection of the fragmented and decayed parts of Dorcas's physicality that mirrors the novel's investigation into Violet's psychology. The image of the "pecking pigeon" draws attention of the metafictional comment that underpins Morrison's "dissection" of the linguistic "parts" of her novel.

The immediate and jarring interruptions of the narrator into the world of the narration serves to disrupt the story even further, posing the text as a construction and revealing the problem of narration, i.e., how can the narrator/creator exist independently from his or her reality/fiction? The narrator's continual reconfiguration of Dorcas mirrors Violet's attempt to reconfigure the past out of pieces and fragments of the story, aligning the narrator's metafictional agenda with Violet's historical one: The narrator is to the text as Violet is to Dorcas. They challenge, negotiate, and deconstruct the boundaries of story-telling and identity making. The slippery narration blurs their two voices and is a language that is never sure if its own obscurity exists in reference to the narrator's attempt to expose or to Violet's desire to compose:

One thing, for sure, she needed her ends cut. In the photograph and from what Violet could remember from the coffin, the girl needed her ends cut. Hair that long gets fraggely easy. Just a quarter-inch trim would do wonders, Dorcas, Dorcas. (Morrison, 2004, p. 15) 
Violet's desire to “cut” Dorcas' hair is aligned with the narrator's attempt to “remember” her story, and this is similar to the notion of figuratively “cutting” Dorcas out of her re-membered but fractured "parts”. However, the narrative's failure to reconstruct Dorcas into a totally rounded and knowable story serves to represent the irrepresentability of the past, of memory, and of its story. Instead, we are left with the "fraggely" pieces foreshadowing the impossible quest for meaning. As the passage suggests, the novel does not attend to a modern sensibility of nostalgia for the past, nor is it a simplistic rejection of it. As Hutcheson argued in her book, A Poetics of Postmodernism: History, Theory, Fiction (1988), the common misconceptions of postmodernist intertextuality is one of mere repudiation of the past; instead, she suggests that the postmodern novel does not serve to reject the notion of past but argues that "there is a problematizing of it" (Hutcheson, 1988, p. 222). The passage wonders about Dorcas, repeating her name two times. This repetition reverberates her two fold nature as she traverses traditional boundaries between the real and the unreal, fantastic and realistic, memory and story, and death and rebirth. The novel's tendency to "play" with language serves to raise what is at stake in it. As Hutcheon claims: "It is not simply a case of novels metaficitonally reveling in their own narrativity or fabulation; here narrative representation—story telling—is a historical and political act” (Hutcheson, 1988, p. 223).

\section{The Shattered Self and Its Ultimate Death in Jazz}

In raising the issue of narrative representation, Morrison thematizes the politics of representation-its anxieties and attractions, its powers and limitations. The thematic dissolve between memory and history, draws attention to the racial and gender codes that determine and constitute identity according to hegemonic codes. Morrison inquires upon the systematic trappings that legitimize the making of the self, presenting identity as an entity that is perpetually predetermined by its politicized precedent.

As Morrison continually crosses generic boundaries of the novel, Violet's transitive sense of self mirrors this pattern, engaging the novelistic tendency at a thematic level. Violet's obsession with Dorcas-her extreme violence-in the opening scene of the novel is transformed into a kind of possession, the physical attempt to be like Dorcas (“do her dance”) and the following psychological desire for her. That is, Violet “wonders if she isn't falling in love with her too” (Morrison, 2004, p. 15) transforming the metaphoric obsession of Dorcas into a literal “possession”, Violent is possessed by a perverted sort of love or her husband's dead lover. Violet's "falling" in love with Dorcas serves to propagate the narrator's obsession with that body-and what she represents for the novel-by positing Violet as the mechanism of the narrative's revelation of history and articulation of story. Violet becomes the mechanism that blurs the distinction between history and story, as Reynolds argued in Twentieth Century American Women's Fiction: A Critical Introduction (1999), that Morrison enacts “a shared sense of writing as mobility, as a transition between and across styles and discourses” (p. 34). This idea of a break is related to how Violet sees herself as two separate individuals, oscillating between a binary opposition from and mirrored equivalences to Dorcas. Violet's sense of a split self echoes the fragmented voices and mistold stories that underpin the collective whole of African American history that this particular story's personification of loss, abandon, and blues attempts to represent.

The disillusioned self that Morrison ultimately incompletes is related to Rigney’s argument in "Hagar’s Mirror. Self and Identity in Morrison’s Fiction” (1991), that “self in Morrison's fiction is always multiple, contradictory, and ambiguous - if, in fact, a self can be said to exist at all” (Rigney, 1991, p. 52). At a linguistic 
level, Violet is severed into two parts—Violet and "Violent" (Rigney, 1991, p. 75), mirroring the perpetual splitting that takes place on a generic and metafictional level—the tale from its teller. The narrator's description of Violent's "private cracks", speaks to the personal weakness of the character and the fallibility of the narrative, "I call them cracks because that is what they were. Not openings or breaks, but dark fissures", in which "there is no foundation at all, but alleyways, crevices" (Morrison, 2004, p. 23). Even the notion of light-the knowability of the story is undermined: "But the globe light is imperfect too. Closely examined it shows seams, ill-glued cracks and weak places beyond which is anything at all. Sometimes when Violet isn't playing attention she stumbles onto these cracks" (Morrison, 2004, p. 23).

The image of Violet "falling" into the crack mirrors the narrative's "stumbling" into incomprehensible places: "Violet had stumbled into a crack or two. Words connected only to themselves pierce an otherwise normal comment" (Morrison, 2004, p. 23). The psychological fall is transformed into a linguistic one disallowing semiotic operation. Morrison's conflation between Violet's “secrets” and the story "gaps” speak to the metafictional self-reflexivity of the novel and the tendency of the genre toward unavoidable imperfection; that is, "alleyways, cracks, and crevices" of Violet expose the "gaps and holes" of the story, suggesting the breakdown of language and displaying the story as a construct. Although Morrison breaks down linguistic operations, she does not destroy them: she still tells her story. The final line in this first section resonates in the notion that "maybe everybody has a renegade tongue yearning to be on its own. Violet shuts up" (Morrison, 2004, p. 24). Extricating herself from her own narration, Morrison seeks control of it. However, the resonance of the story—and her participation in it—disallow this break. The narrator, like Violet, Dorcas, and Joe, “yearn to be on their own", expressing the "renegade tongue's" desire to voice itself and name a story, the desire to be separate from the body, a wish for amputation, a plea for autonomy, the will to escape the trappings of its own mechanism. The ghost of Dorcas then both fragments the story yet serves to resurrect its pieces—she haunts the novel's borders yet simultaneously consoles them.

The role of memory encodes the characters and destabilizes the constitution of identify throughout the novel, negotiating the role of memory as a testament of authenticity. Breaking the regularity of memory, Morrison calls into question the culturally embedded value we claim of the authentic, as Waugh argued in Feminine Fiction: Revisiting the Postmodern (2012), "the death of self" is characteristics of all postmodern fictions, relating to the literal death of Dorcas and the figurative loss of self throughout the novel. However, Morrison's treatment of "the death of self" in Jazz further complicates the postmodern conception of a deconstructed self. By killing the fiction's center of signification—Dorcas—she figuratively resurrects that self to a pathological end, creating a frenzied sense of re-birth (in memory, story, history, and all their intersections). That is, Morrison does not simply conform to the conditions of the postmodern novel, but she challenges and expands them as well—Jazz exists beyond the death of its own generic crisis, finding its salvation within the mystical realm of its novelistic transgression.

\section{Disrupting the Boundaries of the Novel in Jazz}

Morrison figures the narration as a generic trick that dissolves and disrupts boundaries of the novel by means of its structural form: improvisation, juxtaposition, contradiction, paradox, and call-and-response (all limitation of jazz devices). The use of call-and-response dialogue allows Morrison to interrogate her own text, asking 
questions through her characters' curiosities and anxieties: "Well, he says, well, no point in picking the apple if you don't want to see how it taste. How does it taste Joe?” (Morrison, 2004, p. 40). The narrative's recollection of Joe's memory of Dorcas interrogates the notion of sin, figuring the apple motif in relation to her as a "trick". The continual connotation of Dorcas as "sweet"-she tastes sweet, she buys sweets, and Joe continuously imagines her at the candy store- exaggerates the characterization of Dorcas as the embodiment of temptation. A motif that the free indirect speech and the call and response nature of the narrative repeat, alluding to the "girl at the candy store" scene throughout the novel and the biblical allusion to which it draws upon, suggesting Dorcas as both the Eve of Eden and the whore of Harlem. However, the narrative complicates this characterization in the following lines, challenging the sinful connotation of the apple and suggesting Dorcas as a sacred body: "On those nights Joe does not mind lying awake next to his silent wife because his thoughts are with this young good God young girl who both blesses his life and makes him wish he had never been born” (Morrison, 2004, p. 40).

Joe's meditative moment imagines his relation with Dorcas within the realm of the sacred, rejecting any moral disgrace and placing their connection within the grace of God. The notion of Dorcas as "God", supposes her as the creator/maker of his universe: he was made "man” for the seventh time, brought about by her "coming”. His desire to return to a pre-mature time (the repetition of youth) and pre-mortal space (before birth) endows Dorcas with another magical power - the ability to un-do time as a sacred body of the divine. The multiplicity of Dorcas' faces allows Morrison to narrate the reading of Dorcas as a constant misreading, working upon the notion of Dorcas as an inalienable sign — she cannot be isolated to a single "body" of meaning. By slipping the lens by which we see Dorcas, our judgment of her is rendered suspect: She is victim and perpetrator: girl and woman, virgin and whore. In fact, Dorcas embodies the contradiction inherent in the archetypal problem of female representation: The sinning temptress and/or the virgin savior, revealing Morrison's refusal to adhere to the hegemonic codes of representation but suggesting her conflation and intersection of these codes as a means to affect her generic revolution. Morrison creates a fictional mythology-Dorcas's carnal destruction leads to her divine constitution-in which Dorcas's process of mystification transgresses the borders of her bodily death, resurrecting her again and again through her multiple representations. As a mythological sign, she requires interpretation, as she is perpetually reborn in her possible (mis)reading.

The dual treatment of Dorcas as both perpetrator and victim mirrors the doubled sense of identity that marks Violet's double consciousness as both Violet and Violent. The role of naming (and the slippage of one's name) in Morrison's fiction is less about claiming oneself than exposing the transience between self and other - a textual manifestation of the racial, sexual, and class divide that socially "splits" bodies. Identity, for Morrison, is never whole and tangible but fractured and elusive, never explicitly certain of its own ambiguity. Disallowing us to determine and therefore isolate their identities, Morrison allows her characters to take on many forms in such a way that the configuration of Violet and the reconfiguration of her as "violent", reveals the linguistic and generic manipulation talking place:

She didn't need the name to be afraid or to know who she was: the star of her niece's funeral. The woman who ruined the service, changed the whole point and meaning to it and was practically all anyone talked about when they talked about Dorcas' death and in the process had changed the woman's name. Violent they called her now. (Morrison, 2004, p. 75)

The transition of Violet—a proper name-into violent—an adjective-grammatically performs her 
transformation. That is, she is no longer Violet, but she is Violent. Morrison makes literal, once again, metaphoric language. Morrison blurs figurative and literal language oscillating between stories of Violet and violence. The transition of characterization and the slippery narrative that speaks "reality" into being engages with an idea of language as equivocal but extends the notion of substitution to its absurd end, servicing the multiplicity of meaning rather than its singularity. Morrison participates in what Baudrillard termed as "simulation”, in his book called Simulacra and Silmulation (1994):

So it is with simulation, in so far as it is opposed to representation. Representation starts from the principle that the sign and the real are equivalent. Conversely, simulation starts from the Utopia of the principle of equivalence, from the radical negation of the sign as value, from the sign as the reversion and death sentence of every reference. Whereas representation tries to absorb simulation by interpreting it as representation, stimulation envelops the whole edifice of representation as itself a simulacrum. (p. 15)

The novel creates a simulated reality, in which the narrative does not "represent” reality, but it pretends to be it, speaking to the irrelevance of reality and its illusion—-for in the end, according to Baudrillard, both terms are obsolete. This transition is figured within the nebulous identity of Dorcas and Violet, suggesting the notion of femininity as both elusive and indefinite.

The final consolation chapter serves as a eulogy for Dorcas' diegetic death, that is, it occurs after her death has been previously narrated and re-narrated, for she is "already dead" at the beginning of the novel. Although Dorcas achieves mortal death, she continues to exist within the telling and retelling of her story, as a mythological body. Morrison uses this mythical language as a way of speaking about a fragmented, dislocated, and distorted social landscape. As the narrator describes, Violet "had deformed Dorcas", figuring her as a manipulated body and so furthering this notion of fragmentation between reality and its representation. "But the space where the photo had been real” (Morrison, 2004, p. 197) is cleverly inserted comment which speaks to the novel's radical agenda-it inverts and subverts normative conventions of storytelling and meaning-making. Claiming the "space" where the photo had been as "real”, Morrison simultaneously inverts the typical relation between representation (the picture) and reality (Dorcas), in which the picture stands in for the real thing. Instead, Morrison reverses this process; the picture is the real thing (or perhaps the only thing). This metafictional distinction - the self-display of one's construction—locates "reality" within the "space" of the apparatus of representation. By removing the local of representation from the image itself-the photograph—and locating it within the space where the picture had been, Morrison further removes the signifier from the signified. In this way, she equalizes and denominates the representative process, in which the narrative serves as reality and reality exists only in its derivative. Although the narrator's deconstruction of her own reality lends itself to social criticism; however, Morrison's brilliant combination of the supernatural and natural worlds serves to reveal and inform the complex "situation of blacks" rather than negate and ignore it. The use of the supernatural does not exclude the natural but functions to distort and disturb it allowing Morrison to affect her political end rather than escape it. Dorcas' oscillation between poles of free heroism-a symbol, an abstract representation — and determined role—a character, a realistic representation—serves to continually complicate her mythology. Morrison's refusal to de-mystify the phantom of Dorcas creates a mythologized text; it requires interpretation, but there is no explanation. In other words, its resolution resides in its irresolution. As an unresolved body, the narrator describes: 
Dorcas should have been prettier than she was. She just missed. She had all the ingredients of pretty too. Long hair, wavy, half good, half bad. Light skinned. never used skin bleach. Nice shape. But it missed somehow. All together it didn’t fit. (Morrison, 2004, p. 201)

Morrison's treatment of Dorcas as an incomplete body confirms Davis' argument: Morrison, then, must capture universal aspirations, without denying concrete reality, construct a myth that affirms community identity without accepting oppressive definitions (Davis, 1982, p. 39). In this way, Morrison's slippage between mythic aspiration and realistic restriction enables her characters to occupy and transcend their social spaces, not suggestive of "get out of the jail free" ideology in order to escape social conditions but as the narrative's tendency to rethink, negotiate, and challenge them by virtue of their transgression. The novel's novelty lies then in its refusal to specify boundary, allowing the narrative to remain sketchy—it requires explanation, calling upon the reader to ask questions and interrogate what lies at stake in the story's "absence” for Morrison values the myth as a way of designing reality, not confining it.

The final chapter of the novel unveils its metafictional nature engaging the reader within the narrator's "interior monologue" that interrogates and questions its agility and fragility, its power and its failure. The moment of exposure is termed "pain” (Morrison, 2004, p. 219), the first word in the chapter, which serves to align the narrator's break with the characters' many traumas. The narrator wonders: “Well, it’s my storm, isn't it? I break lives to prove I can mend them back again” (Morrison, 2004, p. 219), suggesting the retracing of the past as a psychological rehashing of the wounds of that past. The narrator internalized this pain, initially assuming her nominal authority over it and ultimately realizing her submission to it: "What, I wonder, what would I be. Without aching words that set, then miss, the mark?” (Morrison, 2004, p. 219). This “missing of the mark”, suggests the narrator's mistaking of her own narrative; i.e., she performs a sort of "self-castration" as Nowlin (1999) argued, in which the teller becomes the amputated part of the tale- she exists as the remainder, the anachronistic player, another version of the phantom limb. The metafictional reflexivity and the subversive tendency of the narrator/narration dynamic invert the normative story telling process—-the story tells the writer's tale:

I thought I knew them and wasn't worried that they didn't really know about me. Now, it's clear why they contradicted me at every turn: they knew me all along...I thought I'd hidden myself so well as I watched them through windows and doors, took every opportunity I had to follow them, to gossip about and fill in their lives and all the while they were watching me. Sometimes they even felt so sorry for me and just thinking about their pity I want to die. (Morrison, 2004, p. 220)

The self-conscious quality of the narrative blurs reality and fiction, in a way that the fiction becomes more real. Morrison speaks of her own invalidity describing her characters as "bust being original, complicated, changeable” while she "overreached and missed the obvious” (Morrison, 2004, p. 220) allowing Morrison's narration here to comment upon her earlier one. In the end, as an enlightened speaker, she recognizes her linguistic failure as a novelistic progression, that is, her characters overtake radically their own stories. The reference to the "miss" of the "mark" as the ultimate "trick" recalls earlier notions of game playing and trickery, in this case, driven to their extremes: physical mortality and figurative castration (I want to die). Morrison extends all linguistic devices (the sign, metaphor, allusion, substitution, and irony) to their operative end, exaggerating the device to approach its inevitable failure. All metaphors collapsed by virtue of Morrison's slippery language and its illusions/allusions. If boundaries are all crossable, the rules of metaphoric operation 
cannot be defined. However, the linguistic failure is less representative of Morrison's amateurism but evidence of her literary genius. As Nowlin (1999) argued:

To appreciate Jazz we must locate the narrator's good faith toward the community precisely in her acknowledged failure to represent it according to the measure of her own textually determined fatalism, a failure signaled by her characters' power to evade a narrative logic of repetition and retribution. (p. 165)

The inability to represent appears not as a failure, then, but a confirmation of Morrison’s political scope. By exposing her inability to "represent" a community, voice, and identity, Morrison reveals what is at stake in that representation: Inevitable loss, problematic conviction, and linguistic in-signification, that is she cannot speak the unspeakable. However, the final chapter offers a sense of restoration for Violet and Joe, consoling the trauma that Jazz resurrects, relives, and ultimately relieves. Despite all radical transgression, the novel's tragic mode adheres to a more classical model in the end. In other words, Morrison's treatment of catharsis and revelation structurally resembles Aristotelian theory. As Reynolds (1999) argued: "Morrison finds in Greek tragedy an exemplary aesthetic: communal, civic, cathartic, and also formally complex-“order” is restored but there is also openness" (p. 205).

The mythic order at the end of the novel does not solve its questions but dissolves them, making use of a classical model in order to affect a postmodern one. This paradoxical ending-restoration of order and ambiguous irresolution—allows Morrison to multiply meaning and possibility. The Greek tradition serves as yet another device to frame the narrative, layering frames within other frames in order to accelerate meaning rather than confine it. As Jazz expands and collapses different spheres, its characters assume different forms, figuratively, linguistically, and politically. As boundaries become more and more crossable, the characters become more and more soluble, crossing between and within worlds/words. The novel functions according to novelistic, mystic, mythic, and classic tradition, allowing Jazz's hybrid formulation to speak about story in different ways. The novel perpetually complicates its enigmatic characters; they are alternately vulnerable and grandiose, tragic and brilliant.

The final address to the reader performs its generic surrender, in which the text asks the reader to participate in the making of the fiction and of the telling of its own mythology. As the narrator admits (in parenthesis to further this moment of intimacy):

I have loved only you, surrendered my whole self reckless to you and nobody else. That I want you to love me back and show it to me. That I love the way you hold me, how close you let me be to you. I like your fingers on and on, lifting, turning. I have watched your face for a long time now, and missed your eyes when you were away from me. Talking to you and hearing you answer-that's the kick. (Morrison, 2004, p. 229)

Morrison folds the narrator's own confession (the metafictional comment) within the thematic one (the characters' eulogy of Dorcas and the loss she embodies), framing the "kick" of the novel within this luminal moment of the text's "literalization": It becomes a parody of itself. Personifying the word, Morrison makes real the figural—a radical inversion of the semiotic and discursive process, in which language speaks to us. We are asked as readers to surrender ourselves - our conventions of order, or system of meaning-making, our readerly expectation — to the crossable lines of the novel, the genre, and the politics of representation. The narrator's call in the final lines, "Say make me" speaks its process of (re)production—it is continually remade by our reading of 
it. As the text becomes the fiction that we make, the narrator is a consequence of our making too. The ultimate surrender at the novel's closure, "You are free to do it and I am free to let you because look, look. Look where your hand are. Now” (Morrison, 2004, p. 229), draws attention to the narrator's concession which calls upon the reader to "Look" at our hands as we hold the book "Now". The narrator's fiction is lost in our holding of it—we are now the Gods of the novelistic universe. Her submission is marked by our admission, as we make and remake the word. Morrison's transgression of conventional boundary between tale and teller, reality and fiction, and reader and writer breaches its generic limitations, extending the novel into the spaces beyond-a space of novelistic immortality that repeats (and perpetuates) its own retro-generation.

\section{Conclusions}

It is only through the lens of postmodernism and metafiction that Morrision's fantastic masterpiece can be approached and analyzed. The novel is filled with postmodernist than any previous novel Morrison has produced. The difficulties of the characters in Jazz are related primarily to the absence or displacement of parents and children, which, in turn, is related to the lack of satisfactory connection to the past. The language also performs that displacement creating fissures, crevices, or holes that cause the reader to experience that sense of displacement too in reading the novel. However, it is in this metafictional postmodernist mode that Morrison is able to expose the debilitating effects of White oppression in which the characters have trouble developing fulfilled selves, because they lack adequate relationships with one or more others, such as parents, spouse, family, neighborhood, community, and/or society.

\section{References}

Baudrillard, J. (1994). Simulacra and simulation. (S. Glaser Trans.). Michigan: University of Michigan Press.

Davis, C. (1982, Summer). Self, society, and myth in Toni Morrison’s fiction. Contemporary Literature, 23(3), 323-342

Hutcheson, L. (1988). A poetics of postmodernism: History, theory, fiction. New York: Routledge.

Morrison, T. (2004). Jazz. New York: Vintage.

Nowlin, M. (1999). Toni Morrison's Jazz and the racial dreams of the American writer (pp. 151-174). Durham: Duke University Press.

Reynolds, G. (1999). Twentieth century American women's fiction: A critical introduction. New York: St. Martin's Press.

Rigney, B. (1991). Hagar's mirror: Self and identity in Morrison's fiction. The voices of Toni Morrison (pp. 277-285). Columbus: Ohio State University Press.

Rubenstein, R. (1998, June). Singing the blues/reclaiming Jazz: Toni Morrison and cultural mourning. Mosaic: A Journal for the Interdisciplinary Study of Literature, 31(2), 147-163.

Waugh, P. (1984). Metaficiton: The theory and practice of self-conscious fiction. London: Routledge.

Waugh, P. (2012). Feminine fictions: Revisiting the postmodern. New York: Routledge. 